\title{
Effectiveness of Assisted Reproduction Techniques as an Answer to Male Infertility
}

\author{
Sandrine Chamayou and Antonino Guglielmino \\ Unità di Medicina della Riproduzione - Via Barriera del Bosco \\ Sant'Agata Li Battiati (CT) \\ Italy
}

\section{Introduction}

The assisted reproductive technologies (ART) are of huge help in the resolution of couple infertility especially for male factor. For an evaluation of male fertility, the semen exam is the first analysis requested. All the procedures for an objective exam and parameters of normality have been worldwide established and described in a manual written by the World Health Organization (WHO).

In the application of ART to obtain the pregnancy of healthy children, there are different levels of invasiveness that take in account both male and female factors. For moderate alteration of semen values, the ART called intra uterine insemination (IUI) is easy to perform because fertilization occurs in vivo. In case of intermediate alteration of semen values, metaphase II oocytes are incubated in a solution of motile spermatozoa in a process called in vitro fertilization (IVF). One spermatozoon penetrates by itself the oocyte membranes and fertilizes it. The development of embryos generated in the laboratory is followed until embryos are in utero transferred or stored in liquid nitrogen. Intra-cytoplasmic sperm injection (ICSI) is a variation of IVF in which the fertilization process is assisted. The elective field of ICSI application is a severe male factor. ICSI can be performed with fresh or thawed, motile or immotile, ejaculated or surgically retrieved (microsurgical epididymal sperm aspiration-MESA, sperm aspiration from the epididymis-PESA or testicle-TESA) spermatozoa. Recently, a new technique called IMSI (morphologically selected sperm injection) was introduced in the clinically assisted reproduction. In this case, the spermatozoon to micro-inject in the ooplasm is accurately chosen according to its morphology and particularly to the number and volume of vacuoles in the head of the cell.

Numerous studies related in vivo and in vitro ART outcomes with male infertility and semen characteristics. The aim of this chapter is to present the effectiveness of ART as an answer to male infertility according to semen alterations (number, motility, morphology), the extraction of the spermatozoa (ejaculated/surgically extracted) and the process it underwent (cryopreservation). Furthermore, it has to be underlined that spermatozoa cryopreservation combined with ART represents a huge opportunity of fertility preservation for cancer patients. The genetic analysis of cells from biopsied embryos produced after ICSI (preimplantation genetic diagnosis-PGD) is an alternative mode of reproduction for couples with high risk in the transmission of male genetic disorder. 


\section{Semen characteristics}

The semen analysis is the basic exam in the determination of male fertility or infertility as it has been early determined a positive correlation between normal semen parameters and male infertility potential (WHO, 1987, 1992).

The semen is a mixture of spermatozoa suspended in secretions from the testis and epididymis which are combined with seminal liquid. The seminal liquid is secreted in $90 \%$ by the prostate and the seminal vesicles, and a small proportion is secreted by bulb urethral glands. The final semen is a viscous fluid that comprises the ejaculate. The total number of spermatozoa reflects the sperm production by the testes and the patency of the posttesticular duct system. The volume of the sample, produced by the accessory glands reflect the secretary activity of the glands. Other important parameters of the sperm function are represented by the vitality, the motility, the morphology and composition of the semen. The semen analysis must be standardized and objective. To emphasize the standardization of analysis procedures and to establish reference values, the WHO wrote a manual where the procedure of semen collection, analysis and the parameters of normality are described. Nowadays the fifth edition is available where the criteria of male infertility has been revised (WHO, 2010).

\subsection{Semen analysis}

This paragraph resumes the procedures for a correct semen collection and laboratory analysis as described by the WHO manual (2010).

Commonly, the semen sample is obtain by masturbation. The semen sample should be collected after a minimum of 48 hours but no longer than seven days of sexual abstinence. The semen sample collection should be completed and two samples should be collected for initial evaluation within an interval of time that should not be less than 7 days or more than 3 weeks. In case of markedly differences between two assessments, additional samples should be analyzed.

The semen analysis is divided in macroscopic analysis and microscopic analysis.

The macroscopic parameters are the semen aspect, the viscosity, liquefaction, the volume and the $\mathrm{pH}$.

The microscopic parameters are the sperm concentration calculated per millilitre $(\mathrm{ml})$, the total number of spermatozoa per ejaculate, the percentage of motile spermatozoa, the sperm vitality, the agglutination of spermatozoa, the spermatozoa morphology and the presence of cellular elements other than spermatozoa. It is recommended to execute all microscopic examinations using a phase-contrast microscope.

The semen analysis must be carried out on a fixed 20 um depth preparation. Depths less than 20 um constrain the rational movement of spermatozoa. Since sperm motility is highly dependent on temperature, the assessment of the motility should be performed at $37^{\circ} \mathrm{C}$.

The concentration of spermatozoa should be determined using the haemocytometer chamber as the 'Newbauer haemocytometer' on a diluted preparation of semen covered with a coverslip. The sperm count should be made of complete spermatozoa (heads 
with tails). Defective spermatozoa (pinheads and tailless heads) should also be counted but recorded separately. If no spermatozoa is detected by microscopy, the entire sample should be centrifuged at $3000 \mathrm{~g}$ for 15 minutes. If no spermatozoa is found after the complete analysis of the centrifuged sample, the semen is qualified as 'azoospermic'. The total sperm number refers to the total number of spermatozoa in the entire ejaculate. This number is obtained by multiplying the sperm concentration by the semen volume.

The grade of progressive motility of the spermatozoa is correlated with the pregnancy rate (Jouannet et al. 1988; Larsen et al. 2000; Zinaman et al. 2000). The sperm motility valuation should be performed close to the liquefaction of the sample, between 30 minutes and one hour after sperm collection. At least five microscopic fields are assessed in a systematic way to classify 200 spermatozoa. The motility of each spermatozoon is graded as 'progressive', 'non-progressive', 'immotile', according to whether it shows:

- Progressive motility (PR): spermatozoa moving actively, either linearly or in a large circle, regardless of speed;

- Non progressive motility (NP): Swimming in small circles, the flagellar forces hardly displacing the head, or when only a flagellar beat can be observed;

- Immotility (IM): no movement.

The vitality is estimated by assessing the membrane vitality of the cells. It is routinely determined for the samples with less than $40 \%$ of progressively motile spermatozoa. The percentage of viable cells normally exceeds that of motile cells. The presence of a large proportion of vital but immotile spermatozoa may be indicative of structural defects in the flagellum (Cheme and Rawe, 2003); a high percentage of immotile and non-viable spermatozoa (necrozoospermia) may indicate epididymal pathology (Wilton et al. 1988; Correa-Perrez et al. 2004).

The term of 'Agglutination of spermatozoa' means that motile spermatozoa stick to each other head-to-head, tail-to tail or in a mixed way, e.g. head-to-tail. The presence of agglutination is suggestive, but not sufficient evidence for, an immunological cause of infertility.

The spermatozoa morphology is determined after cell staining. The most widely recommended staining recommended method used is the Papanicolaou stain. For a spermatozoa to be normal, the sperm head, neck, midpiece and tail must be normal. The head should be oval in shape. Allowing for the slight shrinkage induced by fixation and staining, the length of the head should be 4.0-5.0 um and the width 2.5-3.5 um. The lengthto-width ratio should be 1.50 to 1.75 . There should be a well-defined acrosomal region comprising $40-70 \%$ of the head area. The midpiece should be slender, less than $1 \mathrm{um}$ in width, about one and a half times the length of the head, and attached axially to the head. The morphological sperm defects should be noted as head defects, neck and midpiece defects, tail defects and cytoplasmic droplets. Abnormal spermatozoa generally have a lower fertilizing potential. Morphologically defects are associated with chromosomal abnormalities.

In the microscopic analysis the non- nemaspermic cellular components are also valuated. There are referred as 'round cells' and compound of leukocytes, spermatogenic cells, 
epithelium cells, red cells, prostate cells. A normal ejaculate should not contain more than $5 \times 10^{6}$ round cells $/ \mathrm{ml}$.

The semen analysis can be computer-assisted (Computeur-assisted semen analysis-CASA) (Yeung et al. 1997). The advantage of a computer assisted system for sperm analysis is the ability to obtain precise quantitative data as wells as the potential for the standardization of semen analysis procedures. Nevertheless, the main disadvantages are the lack of standardization procedures and the significant expense of equipment requirement. CASA is a valuable tool for research but the manual semen analysis remains the reference (Amann $e t$ al. 2004). Other tests can be made on semen such as the detection of sperm antibodies, sperm vitality, hypo-osmotic swelling test, assays of the sperm acrosome, sperm penetration assay, hemizona assay, mannose binding assay and assays of sperm DNA integrity and fragmentation.
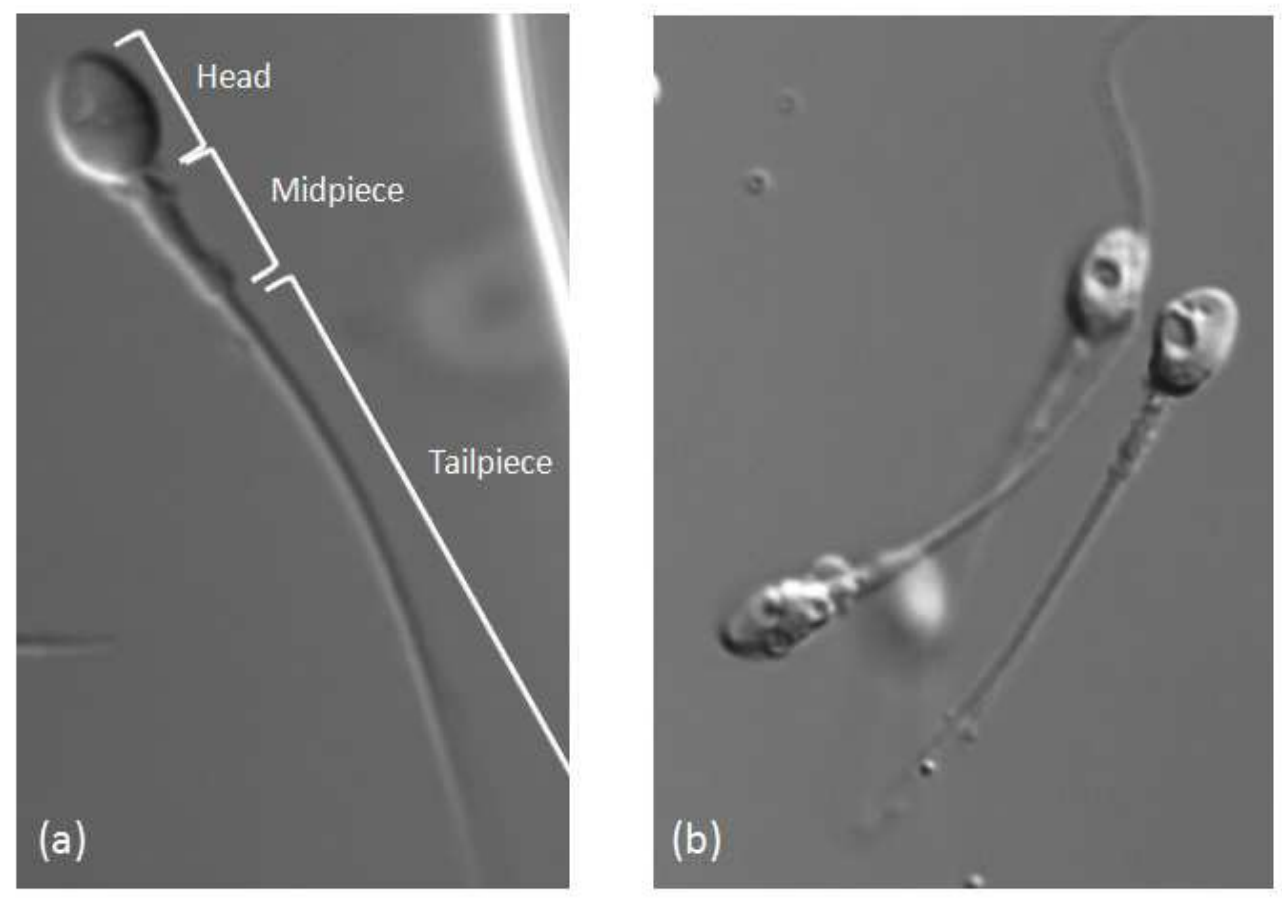

Fig. 1. Spermatozoon with normal morphology (a) and spermatozoa with vacuoles into the head (b).

\subsubsection{Reference values of semen analysis and semen variables}

Tables 1 and 2 summarise the lower references limits of semen characteristics as defined in the fifth edition of WHO manual, and the nomenclature of semen variables. 


\begin{tabular}{|c|c|}
\hline Parameter & Lower reference limit \\
\hline Semen volume (ml) & $1.5(1.4-1.7)$ \\
\hline Total sperm number (106 per ejaculate) & $39(33-46)$ \\
\hline Sperm concentration (106 per ml) & $15(12-16)$ \\
\hline Total motility (PR+NP, \%) & $40(38-42)$ \\
\hline Progressive motility (PR, $\%)$ & $32(31-34)$ \\
\hline Vitality (live spermatozoa, $\%)$ & $58(55-63)$ \\
\hline Sperm morphology (normal form, \%) & $4(3.0-4.0)$ \\
\hline pH & $\geq 7.2$ \\
\hline Peroxidase-positive leucocytes (106 per ml) & $<1.0$ \\
\hline $\begin{array}{c}\text { MAR test (motile spermatozoa with } \\
\text { bound particles, } \%)\end{array}$ & $<50$ \\
\hline Immunobead test (motile spermatozoa \\
with bound beads, \%) & $<50$ \\
\hline Seminal zinc (umol/ejaculate) & $\geq 2.4$ \\
\hline Seminal fruttose (umol/ejaculate) & $\geq 13$ \\
\hline Seminal neutral glucosidase (mU/ejaculate) & $\geq 20$ \\
\hline
\end{tabular}

Table 1. Lower reference limits of semen characteristics ( $5^{\text {th }}$ centiles, 95\% confidence intervals)

\begin{tabular}{|c|c|}
\hline Aspermia & No ejaculate \\
\hline Asthenozoospermia & Less than the reference value for motility \\
\hline Asthenoteratozoospermia & $\begin{array}{l}\text { Less than the reference values for motility and } \\
\text { morphology }\end{array}$ \\
\hline Azoospermia & No spermatozoa in the ejaculate \\
\hline Cryptozoospermia & $\begin{array}{l}\text { No spermatozoa is observed in the fresh preparation } \\
\text { but only after centrifuged pellet }\end{array}$ \\
\hline Hemospermia (Hematospermia) & Presence of leukocytes in the ejaculate \\
\hline $\begin{array}{c}\text { Leukospermia (Leukocytospermia, } \\
\text { pyospermia) }\end{array}$ & $\begin{array}{c}\text { Presence of leukocytes in the ejaculate above the } \\
\text { threshold value }\end{array}$ \\
\hline Necrozoospermia & $\begin{array}{l}\text { Low percentage of live and high percentage of } \\
\text { immotile spermatozoa in the ejaculate }\end{array}$ \\
\hline Normozoospermia & Normal ejaculate as defined by the reference values \\
\hline Oligoastenoteratozoospermia & $\begin{array}{c}\text { Signifies disturbance of all three variables } \\
\text { (concentration or total number, motility, } \\
\text { morphology) }\end{array}$ \\
\hline Oligoteratozoospermia & $\begin{array}{l}\text { Less than the reference values for concentration or } \\
\text { total number and morphology }\end{array}$ \\
\hline Oligozoospermia & $\begin{array}{c}\text { Sperm concentration (or total number) less than the } \\
\text { reference value }\end{array}$ \\
\hline Teratozoospermia & Less than the reference value for morphology \\
\hline
\end{tabular}

Table 2. Nomenclature related to semen variations. 


\subsubsection{Sperm preparation techniques}

In a view to apply diagnostic tests of functions or to use the spermatozoa for therapeutic recovery for intra-uterine insemination (IUI) or in vitro ART, the spermatozoa must be separated from the seminal liquid. While the seminal liquid support the cervical mucus penetration in natural intercourse, the elimination of part of its compounds is necessary to perform IUI or in vitro fertilization (IVF). In the separation of spermatozoa from the seminal liquid, the final preparation concentrates morphologically normal and motile spermatozoa, free from debris, non-germ cells and dead spermatozoa. The separation and concentration of those spermatozoa is done performing a sperm preparation. Three methods are mainly used. The choice of a method is leaded by the semen characteristics. These methods are the simple washing, the direct swim-up and the density gradients. In all the sperm preparations, balanced salt solutions supplemented with proteins and containing an appropriate buffer are used as culture medium.

The 'Sperm washing' is a simple sperm preparation, performed for good quality semen, often used for IUI. The principal is in the washing of the semen to remove the secretive part (WHO, 2010).

The direct swim-up select the spermatozoa on their ability to swim out of the seminal liquid to the culture medium. It is the preferred method for the extraction of motile spermatozoa especially when their percentage is low e.g. for IVF and intracytoplasmic sperm injection (ICSI) (WHO, 2010).

The discontinuous density gradient consists in the centrifugation of the semen on a column of colloidal silica coated with silane which separate the cells according to their density. Furthermore, the motile spermatozoa swim through the gradients and concentrate at the bottom of the tube. This method selects a high fraction of motile spermatozoa and is selective against the debris, the leukocytes, non-germ cells and degenerating germs cells. The discontinuous density gradient is mainly used for IVF and ICSI (WHO, 2010).

If the patient is infected by the human immunodeficiency virus (HIV), the viral RNA and proviral DNA can be found in the seminal liquid and in non-sperm cells. In a view to prevent female partner contamination, a combination of density-gradient centrifugation followed by swim-up can be performed (Gilling-Smith et al. 2006; Savasi et al. 2007). With this combination of procedures, the motile spermatozoa are separated from the seminal liquid and virus-affected non-sperm cells.

\section{ART and results}

In the IUI practice, the female patient is monitored to determine the moment of ovulation; the semen is collected and prepared to select the best spermatozoa to transfer in utero. The fertilization process is in vivo. In IVF and ICSI protocols, the fertilization process is followed and in vitro assisted. Embryos are produced in the laboratory and are subsequently transferred in utero.

\subsection{IUI}

IUI is one of the earliest technique of assisted conception to be applied. It derives from intracervical insemination in which the principle was to deposit a sample of semen (fresh or 
thawed) into the vagina using a catheter. With the development of new sperm preparation and the separation of the motile spermatozoa from the secretive part (Mortimer, 1994), the IUI could be attempted. Concentrated preparation of sperm were attempted directly into the Fallopian tubes, peritoneal cavity, or ovarian follicles of the women, before to reach the consensus that IUI was the most effective method, providing a maximum pregnancy rate with a minimum of complications (Sacks and Simon, 1991). Although IUI can be performed in the natural cycle, nowadays it is combined with ovarian stimulation to increase the pregnancy rate.

The clinical indications for IUI are couples with unexplained infertility, mild or moderate male-factor infertility. This technique can be applied in certain female factors infertility such as antisperm antibodies or hostile cervical environment. In case of male infertility, the presence of ten million of motile spermatozoa is a prerequisite but good results can be obtained with 5 and even one million of motile spermatozoa injected in uterus.

From a technical point of view, on the day of IUI, the patient is asked to produce sperm into a sterile cup. After liquefaction and semen analysis, the sample is treated as previously described to select a high concentration of good motility spermatozoa. The final suspension of selected spermatozoa is concentrated in a maximal final volume of $500 \mathrm{ul}$ of culture medium. IUI can be performed on natural cycle or on female patient that underwent a mild ovarian stimulation. Around the moment of pharmacologically monitored ovulation, the spermatozoa are deposited into the uterus without neither local anesthetic nor antibiotic prophylaxis using polyethylene catheter attached to a plastic syringe. After IUI, the female patient can resume normal activity.

The success rates of IUI depends on the female patient age (De Sutter et al. 2005), the presence of comorbid conditions, ovulation method and the male factor (Burr et al. 1996). Abnormal spermatozoa morphology is associated with poor IUI outcomes on natural cycles and IUI with clomiphene or gonadotropin stimunation (Van Waart et al. 2001). Furthermore, abnormal sperm morphology has been associated with higher IUI complication rates such as miscarriage. Motility and concentration play also an important role in the pregnancy rate expectancy (Montanaro et al. 2001; Ombelet et al. 1997). Patients with percentage of a sperm motility superior to 30 percent have a four time increase cumulative pregnancy rate than patients with sperm motility less than 30 percent (Yalti et al. 2004).

In conclusion, IUI is the most commonly performed ART procedure, a low cost technique and straightforward to perform.

\subsection{IVF}

The first world birth after IVF was obtained but Steptoe and Edwards in 1978 (Steptoe and Edwards, 1978). In 2006, it was estimated that more than three million of babies had been born using this procedure (ESHRE, 2006). The indications for IVF treatment include longstanding infertility due to tubal disease, endometriosis, unexplained infertility, infertility involving male factor.

The principle of IVF is the following: the female partner is given stimulatory drugs (gonadotrophin) in the weeks leading up to the procedure and in a view to trigger the development of several follicules. The follicular fluid are collected in a tube and under 
sedation. The follicular fluid is carefully read in the IVF laboratory and the oocytes that have grown inside the follicules are isolated and incubated. On the same day, the mature oocytes are incubated with an aliquot of fresh (or frozen) motile partner 'spermatozoa. The testtubes or dishes containing the oocytes in the solution of spermatozoa are incubated up to 18 hours at $37^{\circ} \mathrm{C}$ and $5 \% \mathrm{CO}$. A reduced concentration of $\mathrm{O} 2(5-6 \%)$ can also be applied. Between 16 and 18 hours, the fertilization process is checked with the observation of two pronuclei. Tipically, between 60 and $70 \%$ of the oocytes are fertilized. In the following hours, a large majority of fertilized oocytes (now called 'zygotes') reach the embryo-stage with the first cell division. The embryo quality is evaluated on the base the number of cells according to the time of incubation, the absence of extra-cellular fragments, the capacity of the cells to compact at the morula stage and the blastocyst to expanse. The embryos can be maintained in in vitro culture until 5-6 days. Within this period, any embryo can be in utero transferred, discarded or frozen for a successive in utero transfer.

Oehninger et al. (1988) studied the correlation between normal sperm morphology and insemination concentration. By increasing the insemination concentration in samples of severe teratozoospermia, the fertilization rate can be improved.

The couples with male factor and undergoing conventional IVF have a lower fertilization and pregnancy rate expectancy. On the same trend, very low pregnancy rates are obtained with surgical retrieved sperm (Hirsh et al. 1994). As a consequence and if a sufficient number of progressive motility spermatozoa is not available, the assisted reproductive technology called 'Intra-cytoplasmic sperm injection' (ICSI) must be applied as alternative and in a view to assist the fertilization process. The clinical pregnancy rate of IVF across Europe is $26.1 \%$ per egg collection and $29.6 \%$ per embryo-transfer (Andersen et al. 2007), although the success rates decrease according to female age over 35 (HFEA, 2005).

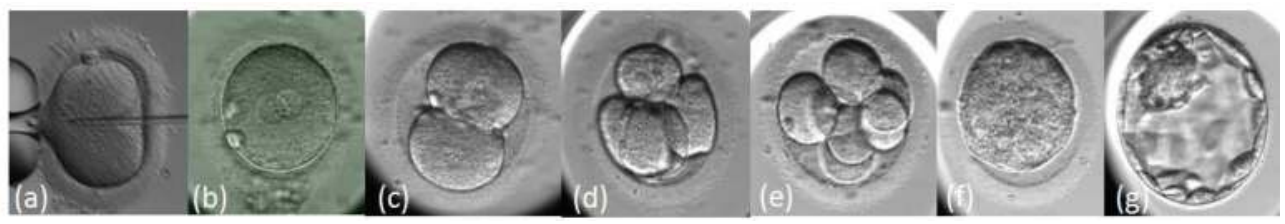

Fig. 2. Embryo development. (a)Time of micro-injection: 0 hour (h); (b) zygote at 17 \pm 1 h; (c) 2 cells at $23 \pm 1 \mathrm{~h}$; (d) 4 cells at $44 \pm 1 \mathrm{~h}$; (e) 8 cells at $68 \pm 1 \mathrm{~h}$; (f) compacting morula at $92 \pm 2 \mathrm{~h}$; (g) blastocyst at $116 \pm 2 \mathrm{~h}$ post ICSI or IVF.

\subsection{ICSI}

\subsubsection{ICSI: History and indications}

On the process of micro-manipulation history that lead to ICSI, the techniques that were previously applied were the partial zona dissection (PZD) to facilitate the sperm penetration (Cohen et al. 1989), the subzonal insemination (SUZI) where the motile spermatozoa were micro-injected under the peri-vitelline space and were in direct contact with the oolemma (Laws-King et al. 1987). Subsequently ICSI of which the principle is the direct micro-injection of a single preferably with good morphology spermatozoon into the ooplasma was invented. The first pregnancies and births was obtained in 1992 (Palermo et al. 1992). Since the beginning, ICSI appeared a superior technique due to higher resutls compared to SUZI 
in terms of oocyte fertilization rate, number of embryos produced and implantation rates (Palermo et al. 1993; Van Steirteghem AC et al. 1993a; Van Steirteghem et al. 1993b).

ICSI can be applied in extremely low sperm counts, impair of motility, poor morphology (oligo-astheno-teratozoospermia) or azoospermia due to impaired testicular function or obstructed excretory ducts. ICSI can also be applied with non progressive motility or immotile spermatozoa. ICSI is the ultimate and only option for successful treatment of male infertility due to obstruction of the excretory ducts and impair of testicular functions.

Table 3 shows the indications for ICSI.

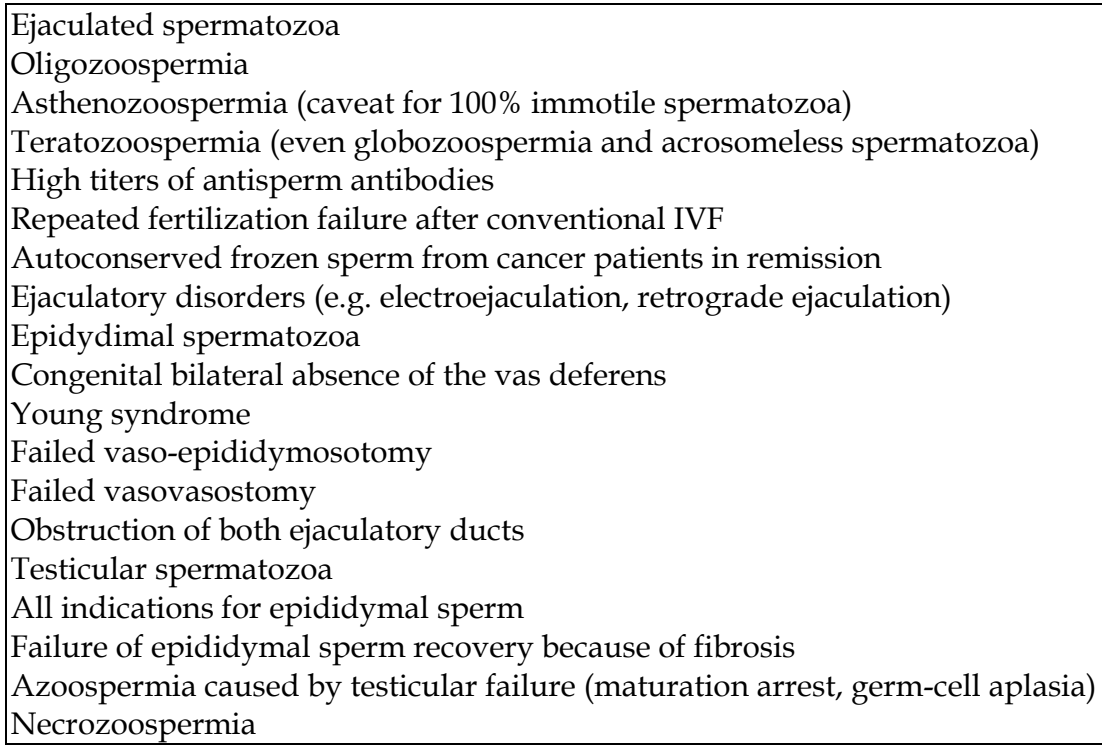

(Van Steirteghem, 2007)

Table 3. Indications for clinical application of ICSI.

The clinical pregnancy rates by use of ICSI are similar to those obtained with IVF, $26.5 \%$ of pregnancy rate according to egg collection and $28.7 \%$ according to embryo-transfer (Andersen et al. 2007). High fertilization and pregnancy rates can be obtained from motile spermatozoa (Nagy et al. 1995) while immotile and dead spermatozoa result in lower fertilization rate (Tournaye et al. 1996).

\subsubsection{ICSI protocol}

As for the IVF procedure, the patient is stimulated and the follicle fluids containing mature (Metafase II) oocytes are aspirated. The retrieved oocytes are incubated in $5 \% \mathrm{CO} 2$ at $37^{\circ} \mathrm{C}$. The difference between IVF and ICSI lays in fertilization method. In a view to perform micro-injection, the cumulus and corona cells surrounding the oocytes must be removed using a combination of enzymatic and mechanical procedures. The assessment of the zona pellucida and the presence or absence of a germinal vesicle and of the first polar body are 
verified at the microscopic observation. The presence and orientation of the meiotic spindle can be assessed when exposed to polarized light. 3.9\% of the intact oocytes are at the metaphase I stage because they underwent germinal vesicle (GV) breakdown but they have not expelled the first polar; $10.3 \%$ of the intact oocytes are at the GV stage, and around $85.8 \%$ of the intact oocytes are in the metaphase II stage, reaching the haploid stage and therefore available for micro-injection (Bonduelle et al. 1999). Matured, denuded and rinsed oocytes are incubated until the time of micro-injection. ICSI can be performed with spermatozoa that have been ejaculated, extracted from epipydimus or testis. As it has been described previously, the sperm is prepared to select motile and good morphology spermatozoa.

The micro-injection of single spermatozoa inside the ooplasm is performed under an inverted microscope equipped with micro-manipulators, microinjectors and heating stage to maintain the temperature at $37^{\circ} \mathrm{C}$. The magnification of $400 \mathrm{X}$ is recommended for the selection of moving spermatozoa. Micromanipulators give the possibility to move the two microinjectors in the 3 directions. The microinjectors can be filled with air or mineral oil and a micrometer controls the plunger. Generally, the holding is fixed to the microinjector on the left of the operator, and the injection pipette is fixed on the right. The oocyte can be fixed, positioned and released by the holding pipette, the spermatozoa is immobilized, injected and released using the injection pipette. It is recommended to position the microscope on a vibration-proof table.

For the micro-injection setting, the gametes (metaphase II oocytes to be micro-injected and spermatozoa to micro-inject) are deposed within micro-droplets of buffered medium and on the same plastic micro-injection dish. The micro-droplets are covered by mineral oil. The micro-drop containing the spermatozoa is a mixture of spermatozoa plus PVP. The PVP slows down the spermatozoa motility and facilitates the manipulation and the control of the fluids. For ejaculated spermatozoa, they should be deposited on a single micro-drop, while extracted spermatozoa from testis or epididymis can be deposited on several microdroplets. Each denuded oocytes is placed on a single micro-drop-droplet (usually eight micro-droplets contain eight oocytes on the micro-injection dish). After the preparation of the dish with the gametes to use, the ICSI is performed. Step by step, ICSI can be described as follows:

- the spermatozoa to micro-inject is chosen on the basis of its good morphology and motility.

- The spermatozoa is immobilised using the injection pipette. Its immobilization is necessary to make the membrane permeable and to allow the release of sperm cytosolic factor which activates the oocyte (Palermo et al. 1993). For spermatozoa immobilization, the cell is positioned at $90^{\circ}$ to the tip of the pipette, which is then lowered gently to compress the sperm flagellum. The shape of the tail should be maintained.

- The immobilized psermatozoon is entered and maintained inside the micro-injection pipette by the flagellum. In other terms, the head is close to the way out of the micropipette.

- The holding pipette is moved slowly to the oocyte.

- The oocyte is held by the suction applied to the holding pipette.

- The oocyte is slowly positioned: the polar body is at the 12 or 6 o'clock position. Nowadays, it is not the polar body that is taken in consideration as reference for oocyte 
orientation but the meiotic spindle. During the oocyte denudation, the polar body can move within the peri-vitellin space. As a consequence, the position of the polar body could not correspond to the meiotic spindle position and the micro-injection can disturb the chromosomes alignment on the equatorial plane of the meiotic spindle and generate aneuploidies.

- The oocyte is maintained in this position and the micro-injection pipette carrying the immobilized spermatozoa is moved slowly to the oocyte.

- The spermatozoa is positioned at the end of the injection pipette.

- The micro-injection pipette penetrates the zona pellucida and the ooplasma at the 3 o'clock position.

- The ooplasma is aspirated gently inside the micro-injection pipette until the observation of the sudden oolemma break.

- The aspiration is immediately stopped.

- The ooplasma is released from the micro-injection pipette and this way out movement is completed when the spermatozoon is completely released into the ooplasma.

- The micro-injection pipette is slowly removed from the oocyte.

- The oocyte is released from the holding pipette.

When all of the oocytes of the dish have been microinjected, the dish is removed from the microscope and the oocytes are incubated in non-buffered medium in $5 \%$ of $\mathrm{CO} 2$ at $37^{\circ} \mathrm{C}$.

Differences in the oolemma breakage have been observed. The immediate break of the oolemma without any aspiration is associated with lower oocyte survival rates (Palermo et al. 1996).

As in the IVF protocol, the fertilization process is checked 16-18 hours after microinjection and embryo culture is prolonged until the destiny of each embryo is decided (transferred, frozen or discarded). As in IVF, abnormal fertilization can be observed with the formation of one pronucleus (about 3\% of the micro-injected oocytes), and the finding of three pronuclear (3PN-about $4 \%$ of micro-injected oocytes) after the micro-injection of one single spermatozoon can be the consequence of extrusion failure of the second polar body at the time of fertilization (Staessen et al. 1997). No embryo generated from $1 \mathrm{PN}$ and 3PN oocytes must be transferred. About $90 \%$ of the $2 \mathrm{PN}$-oocytes cleave and become embryos.

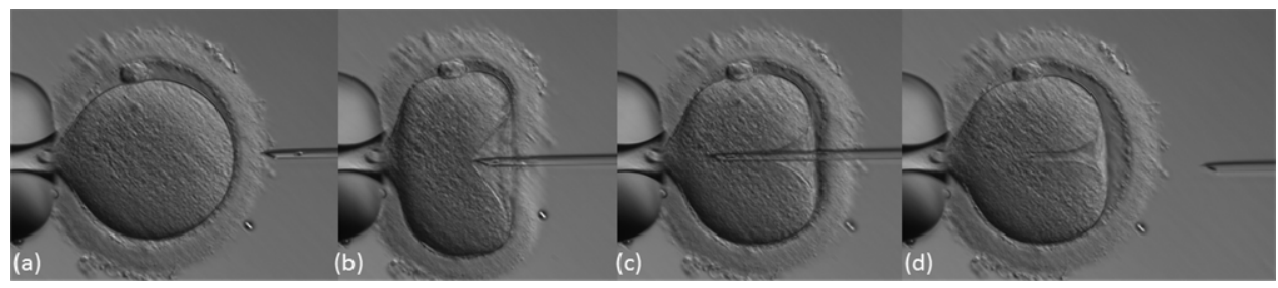

Fig. 3. Intracytoplasmic sperm injection procedure. The oocyte and the micro-injection pipette with the spermatozoon are positioned (a). The micro-injection pipette with the spermatozoon at its end goes through the zona pellucida, the peri-vitellin space (b) and penetrates the oolemma (c). The micro-injection pipette is removed after that the spermatozoon has been released into the ooplasma (d) (with the kind collaboration of C. Ragolia). 


\subsection{ICSI with surgical spermatozoa}

In patients that appear to be azoospermic after semen analysis, the surgical sperm retrieval is the last option to collect spermatozoa. The different techniques are percutaneous epididymal sperm aspiration (PESA), testicular sperm aspiration (TESA), testicular sperm extraction (TESE), and microsurgical epididymal sperm aspiration (MESA). The choice of the technique depends on the type of patient and of the diagnosis.

In all surgical sperm retrieval, ICSI is the method of choice to obtain a pregnancy using fresh or frozen/thawed spermatozoa.

\subsubsection{PESA}

PESA is the least invasive surgical sperm retrieval technique. The patient is in conscious sedation and/or spermatic cord blockage with marcaine or lidocaine. The testis is immobilized and the aspiration is carried out with a $25-\mathrm{G}$ butterfly needle. The fluid is aspirated and examined under microscope to check for motile spermatozoa. The recovered spermatozoa can be subsequently cryopreserved. The percentage of motile spermatozoa retrieval is $93 \%$ (Ramos et al. 2004).

\subsubsection{TESA, TESE and micro-TESE}

Testicular sperm retrieval can be performed either on open surgical biopsy or as a percutaneous procedure. The term 'Testicular sperm extraction' (TESE) qualifies the open biopsy, and the term 'testicular sperm aspiration' (TESA) qualifies the percutaneous retrieval (Schlegel et al. 1998). The open surgical biopsy provides a higher quantity of tissue for harvesting spermatozoa than as aspiration procedure does. Nevertheless, TESA is generally sufficient for spermatozoa retrieval in patients with obstructive infertility and normal spermatogenesis. TESA is performed under local anesthesia. The transcutaneous aspiration uses a needle of 19-21 gauge directly into the testicular parenchyma and using negative pressure. In case of severely crompromised spermatogenesis, TESE should be the preferred method for harvesting spermatozoa.

TESE is performed after spermatic cord anesthesia with marcaine and a transversal $1 \mathrm{~cm}$ incision through the scrotum and tunica vaginalis down to the tunica albuginea and tissue from the mid anterior surface of the testis.

Microscopic TESE is a conjunction between open biopsy and it is conceptually similar to multibiopsy TESE, with the following differences: a single long testis incision is made to expose a large area of the testicular parenchyma and to access germ cells tubules, and a microscope is used to select the seminiferous tubules to be excised (Schlegel 1999). Since the number of spermatozoa obtained from micro-TESE is low, this procedure is generally performed the same day as eggs retrieval during ICSI.

\subsubsection{MESA}

The microsurgical epididymal sperm aspiration (MESA) is an advance in the therapy of non-reconstructable obstructive azoospermia (Schroeder-Printzen et al. 2000). The epididymis is exposed to a $12 \mathrm{~mm}$ incision made in the scrotal skin, an operating microscope 
is used to identify and open the epidydimal tubule to carry out the epididymal sperm aspiration. In 90 percent of obstructive azoospermia cases, spermatozoa were retrieved from epididymis (Silber et al. 1990, Holden et al. 1997; Patrizio 2000). Nowadays this technique has been substitute by the less invasive PESA method.

\subsection{ICSI Results from surgical retrieved sperm}

The patients with obstructive azoospermia and non-obstructive azoospermia are successfully treated with ICSI using surgically retrieved spermatozoa from epididymis or testis. Numerous literature report ICSI with spermatozoa recovered from epididymis (Silber et al. 1994; Tournaye et al. 1994; Mansour et al. 1996) or testis (Schyosman et al. 1993; Silber et al. 1995). The fertilization and pregnancy rates from obstructive azoospermic patients are comparable to those obtained from patients with ejaculated sperm (Aboughar et al. 1997). In those patients, only the etiology can influence ICSI outcomes. The patients with acquired causes of obstructive azoospermia have higher fertilization (Nicopoullos et al. 2004a). The patients with non-obstructive azoospermia have a statistically significant decrease of fertilization and pregnancy rate when compared to osbstructive azoospermic patients (Nicopoullos et al. 2004b).

\subsection{IVF and ICSI results}

Beyond the male factor, the efficacy of all assisted reproductive technique is directly correlated with female age with a significant pregnancy expectancy over 40 years old (Oehninger et al. 1995; Devroey et al. 1996).

With ICSI, lower rated in terms of fertilization and pregnancy rates can be expected when no motile spermatozoa are available.

It is now an overall consensus that the health of the children born from ART is the most important outcome parameter that has to be considered (Wennerholm et al. 2004). Pregnancy complications, major malformations, possible reasons for adverse outcome as well as the increase of multiple ART pregnancies must be taken under consideration. According to Jackson et al. (2004) and when compared to spontaneous conceived singleton children, the IVF and ICSI pregnancies are associated with higher odds of each perinatal mortality, pre-term delivery, low birth weight, very low birth weight and small gestation age. In twin pregnancies, the perinatal mortality is lower in assisted conception compared to spontaneous twins conceptions (Helmerhost et al. 2004). There is an overall increase for major congenital malformations after IVF and ICSI compared to spontaneously conceived children (Hansen et al. 2005) but no significant differences when IVF and ICSI are compared among them (Rimm et al. 2004). The possible causes of malformations are the abnormal caryotypes of infertile patients and properly in abnormal spermatozoa (Bonduelle et al. 1999). A significative $2.1 \%$ of de novo anomalies are observed when sperm concentrations used for ICSI was below 20 million/ml (Bonduelle et al. 2002). It is possible that ART is associated with a higher risk of imprinting disorder, especially Angelman syndrome and Beckwith-Wiedemann syndrome. However, children born with ART are healthy and develop similar to children spontaneously conceived. General health, growth, and mental and psychomotor development of IVF children do not differ from spontaneously conceived children, even if lower birth weight and prematurity may contribute to some health problems observed (Ludwig et al. 2006). 


\subsection{IMSI}

The first findings on ICSI showed no influence of spermatozoa morphology on ICSI outcomes in terms of fertilization, embryo transfer and pregnancy rate (Hammadeh et al. 1996; Svalander et al. 1996; Gomez et al. 2000). But successively, De Vos et al. (2003) underlined lower fertilization, pregnancy and implantation rates when the injected spermatozoa were morphologically abnormal. These data are supported by evaluating the aneuploidy rate in abnormal spermatozoa. The aneuploidy rates for chromosomes $\mathrm{X}, \mathrm{Y}$ and 18 was $29 \%$ in morphologically abnormal spermatozoa compared to $1.8 \%-5.5 \%$ in morphologically normal spermatozoa from the same sample (Ryu et al. 2004).

In 2002, the method of motile sperm organelle morphology examination was developed (MSOME-Bartoov et al. 2002). The examination is performed using an inverted microscope equipped with high-power Nomarski optics enhanced by digital imaging to achieve a magnification up to 6600X. The ICSI performed with a morphologically selected spermatozoa is called 'intracytoplasmic morphologically selected spermatozoa' (IMSI). In 2009, Nadalini et al. reviewed the benefice of this technique on fertilization rate, embryo quality, implantation and pregnancy rates. Furthermore, the application of IMSI lead to a decrease of abortion rate and major congenital malformation (Berkovitz et al. 2007). As a consequence, the clinical application of IMSI technique highlights the early and late paternal effects on embryo development (Vanderzwalmen et al. 2008). Several studies showed that the correlation between morphologically abnormal head of the spermatozoa and incorrect DNA packaging (Berkowitz et al. 2005; Hazout et al. 2006), DNA-protamine organization (Larson et al. 2000), DNA fragmentation (Franco et al. 2008), numerical and structural chromosome abnormalities (Calogero, 2003; Carrell et al. 2004).

In conclusion, IMSI seems to improve in vitro results in selected group of patients with male factor infertility (Balaban et al. 2011).

\section{Sperm cryopreservation}

\subsection{History and indications for sperm banking}

The history of human sperm cryobiology starts in the late 1940s with the discovery that glycerol protected the spermatozoa from freezing injury (Polge et al. 1949). In 1953, the first pregnancies were reported with the use of artificial insemination in combination with frozen-thawed sperm (Sherman and Bunge, 1953). Finally it was discovered that liquid nitrogen (LN2) leads to a better storage of human sperm with no subsequent loss of the motility when thawed after a long period of banking (Sherman, 1963).

The semen cryopreservation has an important role in the male fertility preservation. Usually, the patients that undergo sperm banking are those that have a high risk in becoming infertile due to surgical or medical treatments such as chemo- or radiotherapy for cancer treatment but it is nowadays commonly used for areas of medicine that rely on the use of potentially cytotoxic drugs including treatments of progressive loss of muscular or neurological function, or for autoimmune conditions (Ranganathan et al. 2002). The oncological treatments can have detrimental effects on the gonad and preclude the survivors from having genetically related children. In these individuals, some degree of fertility can return post-treatment but it cannot be predicted. The incidence of azoospermia is high and 
only 20 to 50 percent of these men eventually recover spermatogenesis (Shin et al. 2005). For these reasons, sperm banking is highly recommended for all patients with malignant disease that wish to preserve their fertility potential (Schover et al. 2002).

Sperm banking can be applied before contraceptive measure (vasectomy), for precautionary measure of fertility because of high risk occupation or activity such as military forces, to prevent infertility due to surgeries for recurrent varicocele or hydrocele (Anger et al. 2003), or in a view to ensure a sample available the day of in vitro treatment. The patients that need special collection such as assisted ejaculated patients with spinal injury, spermatozoa from retrograde ejaculation in urine or surgical collection from the genital tract, found in sperm banking the possibility to cryopreserve spermatozoa for clinical and reproductive subsequent use.

For all the patients that are at risk in losing the fertility due to pre-cited reasons, sperm banking gives a significant psychological support in the hope of future paternity. As a consequence, all males requiring chemo- or radiotherapy, including adolescents should have offered the possibility to store spermatozoa (Kamischke et al. 2004).

Finally, sperm banking plays a crucial role in sperm donation programs.

\subsection{Sperm banking protocols and results}

The success of sperm cryopreservation depends on the maintenance of post-thaw structural and functional integrity. The compartments (i.e. acrosome, flagella, midpiece) of the spermatozoon must be protected in a view to undergo normal fertilization under either in vivo or in vitro conditions. Human spermatozoa are not very sensitive to damage caused by rapid initial cooling (cold shock) and they may be more resistant than other cells to cryopreservation damage because of their low water content $(50 \%)$. Nevertheless, the postthaw motility of human spermatozoa can be ranged between 20 and 50 percent (Sbracia et al. 1997). It is believed that the cause of this decrease could be multiple including diminished integrity of the membranes and cryodamage to the membranes of the intracellular compartments, which affects energy metabolism and synthesis.

Pregnancy rates after IUI with cryopreserved donor semen are often related to sperm quality after thawing, timing of insemination and recipient factors such as age, previous pregnancy with sperm donor and ovulatory and uterine tubal disorders (Le Lannou and Lansac, 1993). If the semen is stored in appropriate conditions, no obvious deterioration of sperm quality should occur depending on the time of storage. Feldschuh et al. (2005) and Clarke et al. (2006) obtained children born after 28 years of sperm storage in liquid nitrogen.

As a single spermatozoa is needed for each single oocyte to micro-inject, cryopreservation of any live spermatozoa is worthwhile. The assisted reproductive technique to apply for the research of pregnancy and using thawed semen depends on the quality of post-thaw semen parameters.

Sperm cryopreservation is a complex process with a special responsibility and potential liability on the laboratory staff. The resources such as vessels, banks, storage room, liquid nitrogen containment and removal, the staff safety and protection, the safety of sample storage in a view to ensure sterility, very stable conditions of temperature and to avoid the cross-contamination with infectious agents between samples in storage (e.g. transmission of 
HIV, or hepatitis B or C via cryopreservation vessels) must be considered. The labeling and traceability of stored samples must be supported by written, validated and applied procedures in a view to insure the safety of its clinical use.

The common practice to obtain sperm to freeze is masturbation but surgical retrieved samples can also be frozen. Every freezing procedure is successive to a semen analysis that states the quality of the sample especially for spermatozoa concentration (and number) and motility. Nowadays, the human sperm storage can be performed in vapor phase or in direct contact with liquid nitrogen itself. The vapor phase may reduce the chances to crosscontamination between siero-discordant samples but at the same time, it can be subject to large temperature gradients inside the vessels. In a view to ensure stable sample conditions, the temperatures should not go above $-130^{\circ} \mathrm{C}$. This condition must be ensured otherwise the direct contact with liquid nitrogen is more stable, safer and recommended for long period storage. Several freezing, sperm bank management protocols (Mortimer 2004; Wolf 1995) and cryoprotectants are available commercially. The WHO laboratory manual for the examination and processing of human semen details a home-made protocol of cryopreservation, storage and thawing of human spermatozoa for normozoospermic samples, oligozoospermic samples and surgically retrieved spermatozoa (WHO, 2010). The cryoprotectant used is glycerol-egg-yolk-citrate.

In the freezing procedure the cryoprotectant is added in a proportion $1 / 2$ to semen at $37^{\circ} \mathrm{C}$. Successively, the mixture is incubated at $30-35^{\circ} \mathrm{C}$ for 5 minutes and filled in $0.5 \mathrm{ml}$ plastic sterile straws or in cryovials. The straws are sealed. The cooling procedure can be performed in programmable freezer or manually. The common cooling program is to cool the straws at $1.5^{\circ} \mathrm{C}$ per minute from $20^{\circ} \mathrm{C}$ to $-6^{\circ} \mathrm{C}$ and then at $6^{\circ} \mathrm{C}$ per minute to $-100^{\circ} \mathrm{C}$. The chamber is than hold at $-100^{\circ} \mathrm{C}$ for 30 minutes to allow the straws to be transferred to liquid nitrogen. In the manual method, the straws are placed at $-20^{\circ} \mathrm{C}$ for 30 minutes, then placed at $-70-79^{\circ} \mathrm{C}$ for 30 minutes and finally in liquid nitrogen $\left(-196^{\circ} \mathrm{C}\right)$.

The straws are placed in plastic storage tubes (mini-goblets) and inserted in large storage goblets within the bank in liquid nitrogen. At this stage, the straws can be transported in appropriate tanks and stable conditions of temperature. At the present time there is no limit of time for the storage of frozen sample.

In the thawing procedure, the straws are removed from liquid nitrogen and placed at room temperature. Within 10 minutes, the straws (or cryovials) are opened and emptied. The post-thaw spermatozoa motility is valuated. The cryoprotectant is removed by washing procedures and the motile spermatozoa are available for clinical use.

In case of oligozoospermic samples and surgically retrieved spermatozoa, the few motile spermatozoa can be frozen for subsequent ICSI previous centrifugation at $1500 \mathrm{~g}$ to concentrate the few motile spermatozoa.

Several samples can be frozen per patient, depending on the quality of the sample and the indication for sperm cryopreservation. As in the other procedures of ART, the identity and updated sierology of the patient must be confirmed at the beginning of each freezing set-up.

In recent studies, Agarwal et al. (2004) reported the outcomes of ART according to the invasivity of the technique with thawed sperm in male cancer survivors. A total of 87 cycles were performed with the respective pregnancy rates: $7 \%$ after IUI, $23 \%$ after IVF and $37 \%$ 
after ICSI. On the same way, Schmith et al. (2004) reported $14.8 \%$ after IUI and $38.6 \%$ after ICSI.

Furthermore, there is no significant difference in quality between fresh and frozen-thawed epididymal or testicular spermatozoa in patients with obstructive azoospermia (Griffiths et al. 2004). The pregnancy rate from fresh and frozen-thawed spermatozoa extracted from the epididymis and testicular are similar among them (Nicopoullos et al. 2004b).

\section{ART and genetic male infertility}

In cases of male infertility due to severe non obstructive azoospermia or severe oligoastheteratozoospermia, a search for the karyotype for peripheral blood and microdeletions of AZF gene on Yp11 region should be performed.

In infertile men, the Klineferter syndrome $(47, \mathrm{XXY})$ is the most common genetic abnormality, which occurs in 1 of 500 live male births and is present in $13 \%$ of azoospermic pazients (Rucker et al. 1998). In these patients, spermatozoa can easily be found from surgically intervention and good fertilization rates have been reported (Staessen et al. 2003). Oligozoospermic patients can present autosomal chromosomal aberrations such as Robertsonian and reciprocal translocations (Yoshida et al. 1997).

The prevalence of Y-chromosome microdeletions is $8 \%$ in infertile patients (Pagani et al. 2002). These microdeletions are rare in patients with a spermatozoa concentration higher than 5 millions per $\mathrm{ml}$. The male children of patients with microdeletions will carry the $Y$ defect and it has been reported an association with Turner's stigmata and sexual ambiguity (Patsalis et al. 2002).

In patients with congenital bilateral absence of the vas deferens (CBAVD), mutations in the cystic fibrosis membrane conductance regulator gene (CFTR) should be evaluated. Cystic Fibrosis (CF) is the most common autosomal recessive disease in Caucasians with an incidence of 1 in 2500 and a carrier rate of 1 in 25 . CF mutations is associated with CBAVD in $72 \%$ of the patients, and with Congenital Unilateral Absence of the Vas Deferens (CUAVD) and epididymal obstruction in respectively 30 and $34 \%$ of the patients (Mak et al. 1999). In case of male carrier for CF mutations, the female patients must be screened prior to attempted ICSI and an appropriate genetic counseling must be given to the couple.

Normally, fewer than 30 CAG repeats are present in the exon 1 of androgen receptor gene. The abnormal expansion of repeats would be due to failure in DNA to repair and lead to a severe neurodegenerative syndrome called Kennedy's syndrome (Mak and Jarvi, 1996). Several studies have evidenced an increase of CAG repeats in normal men with idiopathic azoospermic (Yoshida et al. 1999) and in testicular tissue of infertile men (Maduro et al. 2003). Consequently, the future generations may be concerned by accelerated expansion of instable DNA such as CAG repeats.

The preimplantation genetic diagnosis (PGD) allows the couple at risk in the transmission of genetic defects such as chromosomal rearrangements (inherited chromosomal abnormalities), aneuploidy, X-linked diseases, autosomal single-gene disorders such as cystic fibrosis, haemoglobinopathies, Tay-Sachs disease to have an healthy child avoiding therapeutic abortion. Alternatives applications of PGD are for human leukocyte antigen (HLA) typing, nonmedical sex selection, genetic diseases with late onset. The principle 
of PGD is the genetic analysis of a minimum of one embryo cells that should reflect the genetic embryonic inheritance. Only unaffected embryos are transferred in utero. PGD was applied clinically for the first time in 1990 (Handyside et al. 1990) and nowadays the ESHRE PGD Consortium gives updated data of PGD clinical application around the world (Harper et al. 2010).

Imprinting of gene by methylation is an epigenetic phenomenon that regulates the gene expression. Cystidines located within dinucleotide CG repeated sequences are methyled into $\mathrm{CpG}$ islands lying outside the genes'coding regions. Imprinting occurs at different loci during gametogenesis and induces a gender-defined pattern of gene expression. At fertilization time, each gamete brings methylation patterns that are maintained in the offspring. If a failure of imprinting occurs during gametogenesis, two male or two female methylation pattern will be present at fertilization. This event is associated with spedific disease syndrome. In a recent study (Pacheco et al. 2011), CpG methylation profiles and mRNA alterations have been associated with low sperm motility.

The frequency of imprinting disorders such as Beckwith-Wiedemann syndrome and Angelman syndrome are higher in children born after ICSI (Cox et al. 2002; De Baun et al. 2003). The absolute risk is estimated at $1 / 3000$ for Beckwith-Wiedemann syndrome and $1 / 20000$ for Angelman syndrome. This data remains too low to be routinely screened of all ART children born (De Rycke, 2001).

\section{Conclusion}

A couple is considered infertile if no pregnancy is obtained after one year of unprotected intercourse. Infertility affects $15 \%$ of the couples. In $30 \%$ of the cases, pure female or pure male factor are the causes of infertility with an equal proportion. On a general point of view, the male factor is involved in half of the cases.

In the treatment of couple infertility, it has been understood very early that ART would give a big help in reaching the pregnancy of an healthy child. Nowadays it is nearly impossible to calculate how many millions of children were born after assisted reproduction around the world.

In the last decades, huge progresses have been made in helping the infertile male to become father, even in cases of very severe oligoteratoasthenozoospermia, azoospermia and carrying the risk of transmission of defective genetic trait. The sperm banking combined with ART plays a fundamental role in the preservation of male fertility for cancer patients.

In any assisted reproductive technique proposed to the couple to resolve their infertility problem, the patients must be informed on medical procedure and all risks linked to the procedure. The most common risks are hyperstimulation (1-4\% patients) and multiple pregnancies. Around $29 \%$ of all IVF and ICSI cycles results in twin gestation, and $5 \%$ results in three or more fetus (SART, 2004). Furthermore, an increasing rate of major congenital malformation has been observed after IVF and ICSI, mainly due to the causes of infertility.

In the European Community, the donation, procurement, testing, processing, preservation, storage and distribution of reproductive cells and embryos are regulated in a view to guarantee the quality and the safety of their use and distribution (The European Parliament and the Council of the European Union, 2004) 


\section{References}

Aboulghar MA, Mansour RT, Serour GI et al. (1997) Fertilization and pregnancy rates after intracytoplasmic sperm injection using ejaculated semen and surgically retrieved sperm. Fertility and Sterility, 68, 109-111

Agarwal A, Ranganathan P, Kattal N et al. (2004) Fertility after cancer: a prospective review of assisted reproductive outcome with banked semen specimens. Fertility and Sterility, 81, 342-348

Amann RP and Katz DF (2004) Reflections on CASA after 25 years. Journal of Andrology, 25, 317-325

Andersen AN, Goosens V, Gianaroli L et al. (2007) Assisted reproductive technology in Europe, 2003. Results generated from European registrers by ESHRE. Human Reproduction, 22, 1513-1525

Anger JT, Gilbert BR and Goldstein M (2003) Cryopreservation of sperm: indications methods and results. Journal of Urology, 170, 1079-1084

Balaban B, Yakin K, Alatas et al. (2011) Clinical outcome of intracytoplasmic injection of spermatozoa morphologically selected under high magnification: a prospective randomized study, Reproductive BioMedicine Online, 22, 472-476

Berkovitz A, Eltes F, Paul M et al. (2007) The chance of having a healthy normal child following intracytoplasmic morphologically-select sperm injection (IMSI) treatment is higher compared to conventional IVF-ICSI treatment. Fertility and Sterility, 88, S20

Berkovitz A, Eltes F, Yaari S et al. (2005) The morphological normalcy of the sperm nucleus and pregnancy rate of intracytoplasmic injection with morphologically selected sperm. Human Reproduction 20,185-190.

Bartoov B, Berkovitz A, Eltes F, Kogosowski A, Menezo Y and Baraik Y (2002) Real-time fine morphology of motile human sperm cells is associated with IVF-ICSI outcomes, Journal of Andrology, 23(1), 1-8

Bonduelle M, Camus M, De Vos A et al. (1999) Seven years of intracytoplasmic sperm injection and follow-up of 1987 subsequent children. Human Reproduction, 14(suppl 1), 243-264

Bonduelle M, Van Assche E, Joris $\mathrm{H}$ et al. (2002) Prenatal testing in ICSI pregnancies: incidence of chromosomal anomalies in 1586 karyotypes and relation to sperm parameters. Human Reproduction, 17, 2600-2614

Burr RW, Siegberg R, Flaherty SP, Wang XJ, Matthews CD (1996) The influence of sperm morphology and the number of motile sperm inseminated on the outcome of intrauterine insemination combined with mild ovarian stimulation. Fertility and Sterility, 65, 127-132

Chemes HE, Rawe YV (2003) Sperm pathology: a step beyond descriptive morphology. Origin, characterization and fertility potential and abnormal sperm phenotypes in infertile men. Human Reproduction Update, 9, 405-428

Clarke GN et al. (2006) Recovery of human sperm motility and ability to interact with the human zona pellucida after more than 28 years of storage in liquid nitrogen. Fertility and Sterility, 86, 721-722 
Cohen J, Malter H, Whright G et al. (1989) Partial zona dissection of human oocytes when failure of zona pellucid penetration is anticipated. Human Reproduction, 4(4), 435442

Calogero AE (2003) Absolute polymorphic teratozoospermia in patients with oligoasthenozoospermia is associated with an elevated sperm aneuploidy rate. Journal of Andrology 24, 598-603

Carrll DT, Emery BR, Wilcox AL et al. (2004) Sperm chromosome aneuploidy as related to male factor infertility and some ultrastructure defects. Archives of Andrology 50, 181185

Correa-Perez et al. (2004) Clinical management of men producing ejaculates characterized by high levels of dead sperm and altered seminal plasma factors consistent with epididymal necrospermia. Fertility and Sterility, 81, 1148-1150

Cox GF, Burger J, Lip V et al. (2002) Intracytoplasmic sperm injection may increase the risk if imprinting defects. American Journal of Human Genetics, 71, 162-164

De Baun MR, Niemitz EL and Feinberg AP (2003) Association of in vitro fertilization with Beckwith-Wiedemann syndrome and epigenetic alteration of LIT1 and H19. American Journal of Human Genetics, 72, 150-160

De Rycke M (2001) Epigenetics and ART. Infertility and assisted reproduction, Cambridge University Press, p677-683

De Sutter P, Veldeman L, Kok P et al. (2005) Comparison of outcome of pregnancy after intra-uterine insemination (IUI) and IVF. Human Reproduction, 20, 16421646

De Vos A, Van De Velde H. Joris H et al. (2003) Influence of individual sperm morphology on fertilization, embryo morphology, and pregnancy outcome of intracytoplasmic sperm injection, Fertility and Sterility, 79, 42-8

Devroey P, Godoy H, Smitz J et al. (1996) Female age predicts embryonic implantation after ICSI: a case controlled study. Human Reproduction, 11, 1324-1327

European Society of Human Reproduction and Embryology (ESHRE) (2006) Three million babies born using assisted reproductive technologies. Press release at the 2006 Annual Meeting

Feldschuh J et al. (2005) Successful sperm storage for 28 years. Fertility and Sterility, 84, 1017

Franco JG, Baruffi RLR, Mauri AL et al. (2008) Significance of large nuclear vacuoles in human spermatozoa: implications for ICSI, Reproductive BioMedicine Online, 17(1), $42-45$

Gillin-Smith C. et al. (2006) HIV and reproductive care - a review of current practice. British Journal of Gynaecology, 113, 869-878

Gomez E, Perez-Cano I, Amorocho B et al. (2000) Effects of injected spermatozoa morphology on the outcome of intracytoplasmic sperm injection in humans. Fertility and Sterility, 74, 842-843

Griffiths M, Kennedy CR, Rai J et al. (2004) Should cryopreserved epididymal or testicular sperm be recovered from obstructive azoospermic men for ICSI? BJOG, 111, 12891293

Hammadeh ME, Al-Hasani S, Stieber M et al. (1996) The effect of chromatin condensation (Aniline Blue staining) and morphology (strict criteria) of human spermatozoa on 
fertilization, cleavage and pregnancy rated in an intracytoplasmic sperm injection programme. Human Reproduction, 11, 2468-2471

Handyside AH, Kontogianni EH, hardy K and Winston RM (1990) Pregnancies from biopsied human preimplantation embryos sexed by Y-specific DNA amplification, Nature, 344(6268), 768-770

Hansen M, Bower C, Milne E et al. (2005) Assisted reproductive technologies and the risk of birth defects-a systematic review. Human Reproduction, 20(2), 328-338

Harper JC, Coonen E, De Rycke M (2010) ESHRE PGD consortium data collection X: cycles from January to December 2007 with pregnancy followup, to October 2008, Human Reproduction, Vol.25, No.11 pp. 2685-2707

Hazout A, Dumont-Hassan M, Junca AM et al. (2006) High-magnification ICSI overcomes paternal effect resistant to conventional ICSI. Reproductive BioMedicine Online 12, 19-25.

Helmerhost FM, Perquin DA, Donker D et al. (2004) Perinatal outcome of singletons and twins after assisted conception: a systematic review of controlled studies. BMJ, 328(7434), 261.

Hirsh AV, Mills C, Bekir J et al. (1994) Factors iinfluencing the outcome of in vitro fertilization with epididymal spermatozoa in irreversible obstructive azoospermia. Human Reproduction, 9, 1710-1716

Holden CA, Fuscaldo GF, Jackson P et al. (1997) Frozen.thawed epididymal spermatozoa for intracytoplasmic sperm injection. Fertility and Sterility, 67, 81-87

Human Fertilization and Embryology Authority (HFEA) (2005) The patient's guide. London: HFEA

Jackson RA, Gibson KA, Wu YW et al. (2004) Perinatal outcomes in singletons following in vitro fertilization: a meta-analysis. Obstetricts and Gynecology, 103(3), 551563

Jouannet P. et al. (1988) Male factors and the likelihood of pregnancy in infertile couples. I. Study of sperm characteristics. International Journal of Andrology, 11:379-394

Kamischke A et al. (2004) Cryopreservation of sperm from adolescents and adults with malignancies. Journal of Andrology, 25, 586-592

Larsen L et al. (2000) Computeur-assisted semen analysis parameters as predictors for fertility of men from the general population. The Danish First Pregnancy Planner Study Team. Human Reproduction, 15: 1562-1567

Larson K, DeJonge C, Barnes A et al. (2000) Relationship of assisted reproductive technique (ART) outcomes with sperm chromatin integrity and maturity as measured by the sperm chromatin structure assay (SCSA). Human Reproduction 15, 17171722.

Laws-King A, Trounson A, Sathananthan H et al. (1987) Fertilization of human oocytes by microinjection of single spermatozoa under the zona pellucida. Fertility and Sterility, 48(4), 637-642

Le Lannou D and Lansac J (1993) Artificial procreation with frozen donor semen: the French experience of CECOS. In: Barratt CLR, Cooke ID, eds. Donor insemination. Cambridge, Cambridge University Press: 152-169

LudwigAK, Sutcliffe AG ,Dietrich K, Ludwig M (2006) Post-neonatal health and development of children born after assisted reproduction: a systematic review of 
controlled studies. European Journal of Obstetric Gynecology Reproductive Biology , 127(1), 3-25

Maduro MR, Casella R, Kim E et al. (2003) Microsatellite instability and defects in mismatch repair proteins: a new aetiology for Sertoli-cell-only syndrome. Molecular Human Reproduction, 9, 61-68

Mansour RT, Aboulghar MA, Serour GI et al. (1996) Intracytoplasmic sperm injection using microsurgically retrieved epididymal and testicular sperm. Fertility and Sterility, 65(3), 566-572

Mak V and Jarvi KA (1996) The genetics of male infertility. Journal of Urology, 156, 12451256

Mak V, Zielenski J, Tsui LC et al. (1999) Proportion of cystic fibrosis gene mutations not detected by routine testing in men with obstructive azoospermia. JAMA, 281, 22172224

Montanaro Gauci M, Kruger TF, Coetzee Ket al. (2001) Stepwise regression analysis to study male and female factors impacting on pregnancy rate in an uterine insemination programme. Andrologia,33, 135-141

Mortimer D (1994) Practical Laboratory Andrology. New York, NY: Oxford University Press.

Mortimer D (2004) Current and future concepts and practices in human sperm cryobanking. Reproductive BioMedicine Online, 9, 134-151

Nadalini M, Tarozzi N, Distratis V, Scaravelli G and Borini A (2009) Impact of intracytoplasmic morpholocically selected sperm injection on assisted reproduction outcome: a review. Reproductive BioMedicine Online, 19(3), 45-55

Nagy ZP, Liu J, Joris H et al. (1995) The results of intracytoplasmic sperm injection is not related to any of the three basic sperm parameters. Human Reproduction, 10(5), 11231129

Nicopoullos JDM, Gilling-Smith C and Ramsay JWA (2004a) Does the cause of obstructive azoospermia affect the outcome of intracytoplasmic sperm injection: a metaanalysis. BJU Int, 93, 1282-1286

Nicopoullos JDM, Gilling-Smith C, Almeida PA et al. (2004b) Use of chirurgical sperm retrieval in azoospermic men: meta-analysis. Fertility and Sterility, 82, 691701

Ombelet W, Vandeput H, Van de Putte G et al. (1997) Intrauterine insemination after ovarian stimulation with clomiphene citrate: predictive potential of inseminating motile count and sperm morphology, Human Reproduction, 12, 1458-1465

Oehninger S, Acost AA, Morshedi M et al. (1988) Corrective measures and pregnancy outcome in in vitro fertilization in patients with severe sperm morphology abnormalities. Fertility and Sterility, 50, 283-287

Oehninger S, Veeck L, Lanzendorf S et al. (1995) Intracytoplasmic sperm injection: Achievement of high pregnancy rates in couples with severe male factor infertility is dependent primarily upon female and not male factors. Fertility and Sterility, 64, 977-981

Pacheco SE, Andres Houseman E, Christensen BC, et al. (2011) Integrative DNA methylation and gene expression analyses identify DNA packaging and epigenetic regulatory genes associated with low motility sper. PLOS ONE, 6(6), e20280 
Pagani R, Brugh VMIII, Lamb DJ (2002) Chromosome and male infertility. The Urologic Clinics of North America, 29, 745-753

Palermo G, Joris H, Devroey P et al. (1992) Pregnancies after intracytoplasmic sperm injection of single spermatozoa into an oocyte. Lancet, 340, 17-18

Palermo G, Joris H, Derde MP et al. (1993) Sperm characteristics and outcome of human assisted fertilization by subzonal insemination and intracytoplasmic sperm injection. Fertility and Sterility, 63, 1231-1240

Palermo GD, Alikani M, Bertoli M et al. (1996) Oolemma characteristics in relation to survival and fertilization patterns of oocytes treated by intracytoplasmic sperm injection. Human Reproduction, 11(1), 172-176

Patrizio P (2000) Cryopreservation of epidydimal sperm. Molecular and Cellular Endocrinology, 27, 11-14

Patsalis PC, Sismani C, Quintana-Murci L et al. (2002) Effects of transmission of Y chromosome AZFc deletions. Lancet, 360, 1222-4

Polge C, Smith A and Parkes A (1949) Revival of spermatozoa after vitrification and dehydration at low temperature. Nature, 164, 666

Ramos L, Wetzels AM, Hendriks JC et al. (2004) Percutaneous epididymal sperm aspiration: a diagnostic tool for the prediction of complete spermatogenesis. Reproductive BioMedicine Online, 8, 657-663

Ranganathan P, Mahran AM, Hallak J and Agarwal A (2002) Sperm cryopreservation for men with nonmalignant, systemic diseases: a descriptive stidy. Journal of Andrology, 23, 71-75

Rimm AA, Katayama AC, Diaz M et al. (2004) A meta-analysis of controlled studies comparing major malformation rates in IVF and ICSI infants with naturally conceived children. Journal of Assisted Reproduction and Genetics, 21(12), 437443

Rucker GB, Mielnik A, King P et al. (1998) Preoperative screening for genetic abnormalities in men with nonobstructive azoospermia before testicular sperm extraction. Journal of Urology, 160, 2068-2071

Ryu HM, Lin WW, Lamb DJ et al. (2004) Increaesed chromosome X, Y, and 18 nondisjunction in sperm from infertile patients that were identified as normal by strict morphology: implication for intracytoplasmic sperm injection. Fertility and Sterility, 76, 879-883

Sacks PC and Simon JA (1991) Infectious complications of intrauterine insemination: a case report and literature review. International Journal of Fertility, 36, 331-339

Savasi V. et al. (2007) Safety of sperm washing and ART outcome in 741 HIV-1serodiscordant couples. Human Reproduction, 22, 772-777

Sbracia M, Grasso J, Stronk J and Huszar G (1997) Hyaluronic acid substantially increases the retention of motility in cryopreserved/thawed human spermatozoa. Human Reproduction, 12, 1949-1054

Schlegel PN, Su LM and Li PS (1998) Gonadal sperm retrieval: potential for testicular damage in non-obstructive azoospermia. In Fillicori \& C. Flamigni, eds. Treatment of Infertility: The new frontiers. New Jercy, NJ: Communications Media for Education, 383-392

Schlegel PN (1999) Testicular sperm extraction; micro dissection improves sperm yield with minimal tissue excision. Human Reproduction, 14, 131-135 
Schyosman R, Vanderzwalmen P, Nijs M et al. (1993) Successful fertilization by testicular spermatozoa in an in vitro fertilization programme. Human Reproduction, 8(8), 13391340

Schmith KL, Larsen E, Bangsboll S et al. (2004) Assisted reproduction in male cancer survivors: fertility tretmant and outcome in 67 couples. Human Reproduction, 19, 2806-2810

Schover LR, Brey K, Lichtin A, Lipshultz LI and Jeha S (2002) Knowledge and experience regarding cancer, infertility, and sperm banking in younger male survivors. Journal of Clinical Oncology, 20, 1880-1889

Schroeder-Printzen I, Zumbé J, Bispink L (2000) Microsurgical epididymal sperm aspiration: aspirate analysis and straws available after cryopreservation in patients with non-reconstructable obstructive azoospermia. Human Reproduction, 15, 25312535

Sherman JK (1963) Improved methods of preservation of human spermatozoa by freezing and freeze-dying. Fertility and Sterility, 14, 49-64

Sherman JK and Bunge RG (1953) Observation of preservation of human spermatozoa at low temperatures. Preceedings of the Society for Experimental Biology and Medicine. Society for Experimental Biology and Medicine,82, 686-688

Shin D, Lo KC and Lipshultz LI (2005) Treatment options for infertile male with cancer. Journal of the National Cancer Institute Monographs, 34, 48-50

Silber S, Ord T, Balmaceda J, Patrizio P and Asch RH (1990) Congenital absence of the vas deferens: studies on the fertilizing capacity of the human epididymal sperm. New England Jurnal of Medicine, 323, 1788-1792

Silber S.J, Nagy ZP, Liu J et al. (1994) Conventional in vitro fertilization versus intracytoplasmic sperm injection for patients requiring microsurgical sperm aspiration. Human Reproduction, 9(9) 1705-1709

Silber S.J, Van Steirteghem AC, Liu J et al. (1995) High fertilization and pregnancy rate after intracytoplasmic sperm injection with spermatozoa obtained from testicular biopsy. Human Reproduction, 10(1), 148-152

Society for Assisted Reproductive Technology and Centers for Disease Control and Prevention (2004) ART success rates: national summary and fertility clinic reports. www.cdc.gov/reproductivehealth

Staessen C and Van Steirteghem AC (1997) The chromosomal constitution of embryos developing from abnormal fertilized oocytes after intracytoplasmic sperm injection and conventional in vitro fertilization. Human Reproduction, 12(2), 321327

Staessen C, Tournaye H, Van Aasche E et al. (2003) PGD in 47,XXY Klineferter's syndrome patients. Human Reproduction Update, 9, 319-330

Steptoe PC and Edwards EG (1978) Birth after the re-implanted of a human embryo. Lancet, 2,366

Svalander P, Jakobsson AH, Forsberg AS, Bengtsson AC, Wikland M (1996) The outcome of intracytoplasmic sperm injection is unrelated to "strict criteria" sperm morphology. Human Reproduction, 11, 1019-1022

The European Parliament and the Council of the European Union (2004) DIRECTIVE 2004/23/EC OF THE EUROPEAN PARLIAMENT AND OF THE COUNCIL of 31 March 2004 on setting standards of quality and safety for the donation, 
procurement, testing, processing, preservation, storage and distribution of human tissues and cells, Official Journal of the European Union, L 102/48-58

Tournaye H, Devroey P, Liu J et al. (1994) Microsurgical epididymal sperm aspiration and intracytoplasmic sperm injection : a new effective approach to infertility as a result of congenital bilateral absence of the vas deferens. Fertility and Sterility, 61(6), 10451051

Tournaye H, Liu J, Nagy Z et al. (1996) The use of testicular sperm for intracytoplasmic sperm injection in patients with necrozoospermia. Fertility and Sterility, 66(2), 331334

Van Steirteghem AC, Liu J, Nagy Z et al. (1993a) Higher success rate by intracytoplasmic sperm injection than by subzonal insemination: report of a second series of 300 consecutive treatment cycles. Human Reproduction, 8(7), 1055-1066

Van Steirteghem AC, Nagy Z, Joris H et al. (1993b) High fertilization and implantation rates after intracytoplasmic sperm injection. Human Reproduction, 8(7), 10611066

Van Steirteghem AC (2007) Assisted Fertilization. In vitro fertilization, a practical approach. Eds Informal Healtcare USA, Inc.

Van Waart J, Kruger TF, Lombard CJ, Ombelet W (2001). Predictive value of normal sperm morphology in intrauterine insemination (IUI): a structural literature review. Human Reproduction Update, 7, 495-500

Vanderzwalmen P, Hiemer A, Rubner P et al. (2008) Blastocyst development after sperm selection at high magnification is associated with size and number of nuclear vacuoles. Reproductive BioMedicine Online, 17(5), 617-627

Wennerholm UB and Bergh C (2004) what is the most relevant standard of success in assisted reproduction? Singleton live births should also include preterm births. Human Reproduction, 19(9), 1943-1945

Wilton LJ et al. (1988) Human male infertility caused by degeneration and deaths of sperms in the epididymis. Fertility and Sterility, 49, 1051-1058

Wolf DP (1995) Semen cryopreservation. In: Keye WR et al., eds. Infertility evaluation and treatment. Philadelphia, WB Saunders, 686-695

World Healt Organization (1987) WHO Laboratory Manual for the Examination of Human Semen and Sperm-Cervical Mucus Interaction. Cambridge University Press, Second edition. Cambridge.

World Healt Organization (1992) WHO Laboratory Manual for the Examination of Human Semen and Sperm-Cervical Mucus Interaction. Cambridge University Press, Third edition. Cambridge.

World Healt Organization (2010) WHO Laboratory Manual for the Examination and Processing of Human Semen. Cambridge University Press, Fifth edition. Cambridge.

Yalti S, Gurbuz B, Sezer H, Celik S (2004) Effects of semen characteristics on IUI combined with mild ovarian stimulation, Arch Androl, 50(4), 239-246

Yeung CH, Cooper TG, Nieschlag E (1997) A technique for standardization and quality control of subjective sperm motility assessment in semen analysis, Fertility and Sterility, 67, 1156-1158

Yoshida A, Miura K, Shirai M (1997) Cytogenetic survey of 1007 infertilt males. International Journal of Urology, 58, 166-76 
Yoshida KI, Yano M, Chiba K, Honda M, Kitahara S (1999) CAG repeat length in the androgen receoptor gene is enhanced in patients with idiopathic azoospermia, Urology, 54, 1078-1081

Zinaman MJ et al. (2000) Semen quality and human fertility: a prospective study with healthy couples. Journal of Andrology, 21: 145-153 


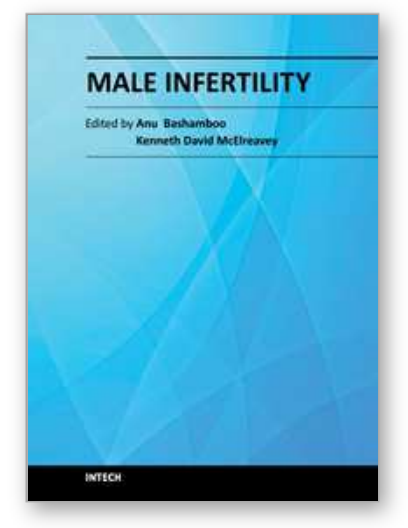

\author{
Male Infertility \\ Edited by Dr. Anu Bashamboo
}

ISBN 978-953-51-0562-6

Hard cover, 194 pages

Publisher InTech

Published online 20, April, 2012

Published in print edition April, 2012

Male infertility is a multifaceted disease where genetic, epigenetic and environmental factors all contribute to the development of the phenotype. In recent years, there has been an increasing concern about a decline in reproductive health, paralleled by an increase in demand for infertility treatments. This calls for a detailed and thorough understanding of normal and aberrant testicular function and the environmental influences on the establishment and integrity of the male germ cell. This is crucial for understanding the complex pathophysiology of male infertility and eventual success of Assisted Reproductive Technologies.

\title{
How to reference
}

In order to correctly reference this scholarly work, feel free to copy and paste the following:

Sandrine Chamayou and Antonino Guglielmino (2012). Effectiveness of Assisted Reproduction Techniques as an Answer to Male Infertility, Male Infertility, Dr. Anu Bashamboo (Ed.), ISBN: 978-953-51-0562-6, InTech, Available from: http://www.intechopen.com/books/male-infertility/effectiveness-of-assisted-reproductivetechniques-as-an-answer-to-male-infertility

\section{INTECH}

open science | open minds

\section{InTech Europe}

University Campus STeP Ri

Slavka Krautzeka 83/A

51000 Rijeka, Croatia

Phone: +385 (51) 770447

Fax: +385 (51) 686166

www.intechopen.com

\section{InTech China}

Unit 405, Office Block, Hotel Equatorial Shanghai

No.65, Yan An Road (West), Shanghai, 200040, China

中国上海市延安西路 65 号上海国际贵都大饭店办公楼 405 单元

Phone: +86-21-62489820

Fax: +86-21-62489821 
(C) 2012 The Author(s). Licensee IntechOpen. This is an open access article distributed under the terms of the Creative Commons Attribution 3.0 License, which permits unrestricted use, distribution, and reproduction in any medium, provided the original work is properly cited. 